Scientił studia, São Paulo, v. 10, n. 3, p. 455-88, 2012

\title{
त्री \\ Valores e incomensurabilidade: meditações kuhnianas em chave estruturalista e laudaniana
}

Valter Alnis BezerRA

\begin{abstract}
电
RESUMO

Neste artigo, são colocados em perspectiva e reinterpretados dois temas que ocupam lugar de destaque dentro da imagem kuhniana de ciência: (1) o papel dos valores e sua relação com a questão da subdeterminação metodológica; (2) a incomensurabilidade e seus dilemas. As teses de Kuhn a respeito desses temas são reavaliadas, seus desdobramentos são criticamente discutidos, e determinadas reinterpretações e reformulações são propostas. Isso é feito segundo duas perspectivas metacientíficas: a visão historiográfica-metametodológica de Laudan (nas variantes reticulacional e de solução de problemas) e a metateoria estruturalista iniciada por Balzer, Moulines e Sneed. Mostra-se que, desse modo, são removidas as principais dificuldades inerentes ao tratamento kuhniano dessas questões, ao mesmo tempo que se consegue preservar os traços mais interessantes e as intuições mais perspicazes de Kuhn a respeito.
\end{abstract}

Palavras-chave $\bullet$ Kuhn. Incomensurabilidade. Laudan. Metateoria estruturalista. Valores.

Metodologia. Racionalidade científica.

"O livro [De Revolutionibus] deu origem a uma revolução que apenas se enunciara. É mais um fazedor de revolução do que um texto revolucionário" (Kuhn, 2002, p. 152).

\section{INTRODUÇÃO}

Nestas meditações, empreende-se uma leitura crítica e uma colocação em perspectiva de dois temas kuhnianos: (1) o papel dos valores e sua relação com a questão da subdeterminação metodológica; e (2) a incomensurabilidade e seus dilemas. Tal estudo é feito segundo duas perspectivas metacientíficas contemporâneas, que possibilitam reinterpretar, contextualizar e expandir esses temas, a saber: a metateoria estruturalista, iniciada por Joseph Sneed e outros, e a visão historiográfica-metametodológica de Larry Laudan (nas variantes reticulacional e de solução de problemas). A metateoria 
estruturalista tem uma longa história de convergência, sob certos aspectos, com as concepções kuhnianas - ainda que, historicamente, tenha sido desenvolvida de maneira independente daquelas. Por outro lado, a visão de solução de problemas de Laudan e, depois, a sua visão reticulacional estiveram, o mais das vezes, em contraponto crítico direto com a visão kuhniana.

Em nossa análise, a visão reticulacional irá desempenhar papel central na análise crítica da doutrina kuhniana acerca dos valores, momento em que já nos deparamos com o problema da incomensurabilidade (meditação 1); a concepção estruturalista irá desempenhar papel crucial na continuação da desconstrução da doutrina da incomensurabilidade, sendo nisso acompanhada, de maneira subsidiária, pelo enfoque de solução de problemas de Laudan (meditação 2). São identificadas cinco formas do fenômeno da incomensurabilidade, que se colocam a partir da imagem de ciência kuhniana, cada uma delas ocasionada por um tipo de variância em algum componente do sistema de conhecimento científico - variância de critérios de escolha teórica, de problemas e de padrões de solução (meditação 1), variância de significado e de exemplares (meditação 2). Uma dessas formas, a incomensurabilidade por variância de exemplares, parece, até onde sabemos, não ter sido ainda discutida na literatura. A visão que aqui se defende é de que, ainda que possam existir tais variâncias, enquanto fenômenos cognitivos do desenvolvimento da ciência, é possível desarmar as consequências relativistas e irracionalistas de cada uma delas.

Os temas dos valores e da incomensurabilidade estão indubitavelmente ligados entre si e guardam, por sua vez, relação com as questões mais amplas da racionalidade e do progresso científicos. Independentemente de concordarmos ou não com a maneira pela qual Kuhn equacionou esses e outros temas relacionados, e independentemente de endossarmos ou não as teses que formulou acerca deles, é patente que suas formulações podem e devem ser consideradas como legados perenes que a filosofia da ciência, no século xxI, deve a um de seus mais controversos autores do século xx. Parece claro que, se há um ensinamento que podemos retirar da pesquisa em metaciência no último meio século, é este: que nenhum dos chamados "grandes modelos gerais de ciência" propostos durante as primeiras seis décadas do século xx contém, sozinho, algo semelhante à "verdade" acerca da ciência (seja lá o que "verdade" possa significar). Porém, ao mesmo tempo, também parece claro que Kuhn deixou uma herança que inspira, provoca e, por que não dizer, ocasionalmente também exaspera seus leitores e intérpretes. Mas, acima de tudo, desafia.'

1 Citarei as passagens de $A$ estrutura das revoluções científicas em minha própria tradução a partir da edição em inglês (Kuhn, 1970). Também me referirei abreviadamente a essa obra por Estrutura. 
VAlores e incomensurabilidade: Meditações KuHNianas...

\section{Primeira meditaçÃo: Valores e subdeterminaÇão metodológica}

No Pós-Escrito à segunda edição de $A$ estrutura das revoluções científicas, Kuhn apresenta um quadro da mudança científica em várias passagens (cf. 1970, p. 147-8, 150-3) que, tomadas em conjunto, soam misteriosamente oraculares (o que é frequente em Kuhn), contêm aspectos intrigantes e suscitam uma infinidade de dúvidas e questionamentos. Kuhn sustenta ali que a competição interparadigmática "não é o tipo de batalha que possa ser resolvida por meio de provas" (demonstrações) - em particular, não por meio de argumentos que envolvam a contagem do número de problemas resolvidos por cada um. Isso, prossegue, seria possível caso houvesse "apenas um conjunto de problemas científicos, um mesmo mundo no qual trabalhar neles e um único conjunto de padrões para a sua solução", precisamente o que, segundo ele, não é o caso. Na verdade, os cientistas não seriam levados a realizar a transição entre um paradigma e outro por quaisquer argumentos: o que ocorreria é "uma experiência de conversão que não pode ser forçada". O que está em jogo nessas situações, mais do que a argumentação, seria a persuasão. Quanto às razões que podem ser persuasivas, Kuhn observa que elas podem ser dos tipos mais variados, alguns delas jazendo "inteiramente fora da esfera da ciência", e outras dependendo de "idiossincrasias de natureza autobiográfica ou de personalidade".

Em uma conferência célebre, Kuhn (1989b [1977]) principia citando partes desse mesmo trecho da Estrutura e procura defender-se da acusação de ter reduzido a mudança científica a uma questão de "psicologia das multidões" - a frase de Lakatos é citada por Kuhn, o qual menciona também Shapere e Scheffler entre os acusadores. Nesse artigo, Kuhn procura especificar de maneira mais precisa como se deveria entender suas teses sobre as limitações da metodologia no estabelecimento da objetividade científica. Os argumentos do texto viriam a ser mais tarde alvo de uma minuciosa crítica por parte de Laudan. ${ }^{2}$ Como essa crítica coloca em foco questões centrais sobre o papel dos valores, a incomensurabilidade e o relativismo na escolha teórica, valerá a pena determo-nos para considerar com atenção os argumentos e suas implicações, bem como as possíveis alternativas.

\section{1.l Ambiguidade E INGONSISTÊNCIA MÚtUA DOS GRITÉRIOS}

No início de seu texto (1989b [1977]), Kuhn exemplifica que tipo de critérios tem em mente quando fala sobre os critérios de escolha teórica - os cinco exemplos por ele

2 Ver "Kuhn's critique of methodology" publicado como parte do capítulo 4, de Laudan (1984), e também como um artigo autônomo, Laudan (1985), e depois incorporado ao capítulo 5 de Laudan (1996). 
citados são precisão, amplitude, consistência, simplicidade e fertilidade - critérios que poderíamos chamar de metodológicos, ou seja, qualidades que se deseja que uma "boa" teoria apresente no máximo grau possível. A seguir, Kuhn aponta dois grandes problemas principais para a sua utilização como fundamento das escolhas científicas. Primeiro, os critérios metodológicos são intrinsecamente ambíguos na sua aplicação "imprecisos", escreve Kuhn: "Quando os cientistas têm de escolher entre teorias rivais, dois homens comprometidos completamente com a mesma lista de critérios para escolha podem, contudo, chegar a conclusões diferentes" (1989b [1977], p. 386-8).

O segundo problema é que os critérios de escolha compartilhados, quando tomados coletivamente, podem revelar-se mutuamente inconsistentes. Afirma Kuhn: "Quando desenvolvidos em conjunto, [os critérios] mostram repetidamente entrar em conflito uns com os outros" (1989b [1977], p. 386). Ora, se diferentes padrões metodológicos apontam em diferentes direções, o cientista poderia perfeitamente tomar a direção que lhe aprouvesse. Porém, a situação é ainda mais delicada, pois o cientista poderia atribuir maior ou menor peso a este ou àquele critério. Dessa maneira, cientistas que concordam acerca dos critérios $e$ da sua interpretação poderiam, mesmo assim, chegar a avaliações conflitantes (1989b [1977], p. 388).

Kuhn retira daí uma consequência forte, a de que "devemos ir além da lista de critérios partilhados, para as caraterísticas dos indivíduos que fizeram a escolha. (...) Todo caso individual de escolha teórica envolve uma mistura de fatores objetivos e subjetivos, ou critérios partilhados e individuais" (1989b [1977], p. 388-9, grifo nosso), visto que os critérios "objetivos" partilhados seriam ambíguos e insuficientes para fundamentar esta ou aquela preferência. Resumindo, "no que respeita a divergências desse gênero, nenhum conjunto de critérios de escolha já proposto é útil. (...) [os critérios de escolha] não são por si suficientes para determinar as decisões dos cientistas individuais" (1989b [1977], p. 388, grifo nosso).

A seguir, Kuhn considera uma interessante objeção que poderia ser levantada. É possível que, coletivamente e a longo prazo, as decisões coletivas tendessem estatisticamente a convergir para um perfil de preferência comum, unânime? Isso pareceria ser uma indicação de que os algoritmos de avaliação individuais (tais como, por exemplo, os algoritmos bayesianos) também tendem a tornar-se idênticos, e o processo, em última análise, objetivo. Porém Kuhn não cede. Ele sustenta que, ainda que os algoritmos de escolha possam tornar-se, com o tempo, mais parecidos entre si, "os algoritmos dos indivíduos são, em última instância, todos diferentes, em virtude das considerações subjetivas com que cada um deve completar os critérios objetivos, antes que se possa realizar quaisquer cálculos" (1989b [1977], p. 393-4).

Essas duas teses kuhnianas foram apelidadas por Laudan, respectivamente, de "argumento da "ambiguidade dos padrões partilhados"” e "argumento da "inconsistência 
VALORES E Incomensurabilidade: MEditações KuHNiANAS...

coletiva das regras'” (cf. 1984, p. 88, 92; 1996, p. 89, 93). Ao discuti-los criticamente, Laudan observa que Kuhn propõe ambas as teses como enunciados universais acerca dos sistemas criteriológicos. Os critérios seriam em geral ambíguos, seriam em geral mutuamente inconsistentes. A desconstrução do argumento kuhniano à maneira laudaniana requer que se coloque em jogo a noção de valor.

\subsection{Os GRITÉRIOS COMO VALORES}

Kuhn lança, aproximadamente a partir da metade do texto (1989b [1977], p. 395), sua proposta para tentar compreender como critérios embebidos de elementos subjetivos podem, ainda assim, ser eficazes na justificação das escolhas teóricas. Como pode haver decisão minimamente racional, propriamente falando, diante da subdeterminação diagnosticada anteriormente? A sua proposta é que "os critérios de escolha (...) funcionam não como regras, que determinam a escolha, mas sim como valores, que a influenciam". É por isso, segundo ele, que cientistas comprometidos com os mesmos valores podem tomar decisões diferentes. Embora os valores se mostrem ambíguos - não sendo, por isso, suficientes para configurar nenhum algoritmo partilhado de escolha -, "eles especificam muita coisa: o que cada cientista deve considerar ao tomar uma decisão, o que pode e não pode considerar importante, e o que se lhe pode legitimamente exigir como base para a escolha que fez" (Kuhn, 1989 [1977], p. 395-6).

Temos aqui, portanto, um deslocamento da questão. Kuhn parece supor que os valores teriam com as escolhas científicas uma relação de influência que seria diferente da relação de determinação que caracterizaria os critérios ou as regras. Na visão kuhniana, seria possível uma situação em que um mesmo valor possa ter múltiplas interpretações, e/ou seja aplicado de maneiras diferentes por indivíduos diferentes. Também é possível que aos valores de uma mesma base axiológica compartilhada sejam atribuídos graus de importâncias ou pesos diferentes. Desse modo, diferentes decisões poderiam ser tomadas com base nos mesmos valores. Por isso, "[as pessoas] podem diferir em suas conclusões sem infringir nenhuma regra aceita" (2006a [1970a], p. 195-6), e "nenhum deles pode ser convencido de erro. E nenhum deles está sendo anticientífico" (2006b, p. 199-200).

A lacuna crucial deixada por Kuhn, no entanto, é que ele não especifica qual seria o mecanismo pelo qual se dá a "influência" dos valores sobre as escolhas teóricas. Um pouco adiante no texto, ele comenta: "mesmo os que me seguiram até aqui desejarão saber como é que um empreendimento baseado em valores do gênero que acabei de escrever pode desenvolver-se como o faz uma ciência, produzindo repetidamente técnicas novas e poderosas de predição e controle". E a sua resposta é um tanto decepcionante, sob um ponto de vista filosófico. "Infelizmente, não tenho qualquer respos- 
ta para a questão, mas isso é apenas outra forma de dizer que não reivindico a resolução do problema da indução" (1989b [1977], p. 397). Pode-se questionar se essa analogia é correta, pois, afinal, perguntar-se sobre como a metodologia científica pode conduzir a um conhecimento dotado de crescente adequação empírica não é uma questão que se reduz automaticamente ao problema da indução. O mecanismo indutivo pode ter sido historicamente uma das respostas dadas ao problema da conexão metodológica entre meios e fins científicos, porém certamente não é a única.

A reposta de Laudan aos argumentos da ambiguidade e da inconsistência é, em um dos casos, de natureza histórica e, no outro, de natureza filosófica (cf. Laudan 1996, p. 89-94; 1984, cap. 4, 1985). No caso da ambiguidade dos padrões, a resposta é que, pace Kuhn, seria possível encontrar na história da ciência muitos exemplos de critérios de preferência teórica, amplamente compartilhados pelos cientistas, que podem ser aplicados aos casos concretos sem a alegada ambiguidade. Seriam exemplos disso o requisito da consistência lógica, a exigência de fecho dedutivo, a capacidade de prever fatos novos, a exigência de teste/controle experimental. (Isso não significa que alguns critérios não possam ser ambíguos na sua aplicação: um caso notório é o da simplicidade.)

Além disso, no caso da inconsistência mútua das regras, a resposta de Laudan se dá em dois momentos. Primeiramente, ele observa que é possível encontrar na história da metodologia exemplos de cânones metodológicos que não apresentam o tipo generalizado de inconsistência apontado por Kuhn. Em um segundo momento, a resposta se dirige ao caso mais geral, onde não só pode haver critérios inconsistentes, mas também a situação muito mais interessante - e, quiçá, mais frequente - de critérios que são meramente conflitantes, forçando o cientista simultaneamente em direções diferentes. A resposta (apresentada de maneira apenas esboçada) envolve o recurso ao seu modelo reticulacional, somado aos mecanismos de crítica axiológica (cf. Laudan, 1984, p. 1-87). Afinal, trata-se de situações que demandam trabalhar com múltiplos critérios concomitantes, e podem requerer a reconfiguração dos componentes da estrutura reticular. A perspectiva reticulacional, que entende as regras metodológicas como meios para o atingimento de fins cognitivos (vistos como valores), proporciona, precisamente, um mecanismo para a resolução racional das tensões cognitivas e para a reconfiguração gradual do sistema.

Note-se a propósito que, mesmo podendo existir ambiguidade e inconsistência dos valores, acaba acontecendo também a coalescência dada pela homogeneização que (segundo Kuhn) vigora na comunidade científica. As possíveis idiossincrasias individuais que possam surgir no manejo dos valores e dos critérios compartilhados são submersas no monopólio do paradigma. Sem essa uniformização, a própria ciência normal seria impossível. A imagem kuhniana de ciência sugere que a variabilidade individual que possa existir na aplicação dos critérios de preferência teórica, por cada 
VALORES E INGOMENSURABILIDAdE: MEditações KUHNIANAS...

cientista, sofre, ao fim e ao cabo, uma uniformização por força daqueles modos de aplicação e articulação que são consensuais e partilhados na comunidade científica. O individualismo metodológico é, assim, neutralizado a longo prazo, pelo efeito do consenso paradigmático. Por isso, talvez o alarme de Laudan neste ponto de sua desconstrução da "crítica de Kuhn à metodologia" seja excessivo, pois, efetivamente, o individualismo metodológico não sobreviveria o suficiente, dentro da comunidade, para dar origem a uma genuína subdeterminação metodológica.

\subsection{A variânGIA DE GRItÉRIOS DE ESGOLHA tEóRICA}

Kuhn apresenta, na parte final do mesmo artigo (1989b [1977]), uma terceira tese, denominada por Laudan (1984, p. 95; 1996, p. 94) o "argumento dos padrões cambiantes" (shifting standards argument). Temos já aqui o germe de uma forma de incomensurabilidade. Kuhn afirma que pode haver variância radical nos próprios critérios que especificam os desiderata de uma teoria científica aceitável (agora já entendidos como valores), bem como na sua ponderação relativa durante as mudanças paradigmáticas. Os valores não estariam fixados de uma vez por todas, nem constituiriam características permanentes da ciência. Notemos que os dois argumentos anteriores tratavam dos efeitos da ambiguidade e da inconsistência mútua de estruturas valorativas acerca de cuja composição existe consenso. Ou seja, tratava-se de situações intraparadigmáticas nas quais as partes estão de acordo quanto à lista de valores vigentes (podendo depois divergir quanto a sua interpretação, aplicação ou ponderação relativa). Agora, porém, Kuhn questiona o pressuposto de que os valores permaneçam fixos ao longo das mudanças científicas, e propõe-nos, assim, situações nas quais há dissenso acerca de quais são os valores relevantes ou aceitáveis ou recomendáveis. "Supus implicitamente que (...) os critérios ou valores postos em jogo na escolha teórica estão fixados de uma vez por todas (...). Porém basta um pouco de conhecimento da história para sugerir que tanto a aplicação desses valores como, mais obviamente, os pesos relativos que lhes estão ligados variaram acentuadamente com o tempo e também com o campo de aplicação". Para Kuhn, essa variância está imbricada na mudança paradigmática: "o que pode parecer particularmente penoso acerca de mudanças como essa é que elas ocorrem em geral na sequência de uma mudança de teoria" (Kuhn, 1989b [1977], p. 4.001). Entre os exemplos por ele oferecidos, estão a redefinição do valor da precisão, desde o período pré-moderno até o século xix, e a minimização do valor da explicação das variações qualitativas, a partir do advento da química de Lavoisier.

Encontramos aqui afinidade com pontos de vista anteriormente expressos por Kuhn acerca da indecidibilidade racional das mudanças científicas como, por exemplo, quando Kuhn (1970, p. 94) escreve que a circularidade é inevitável nos debates 
acerca da escolha entre paradigmas diferentes, pois trata-se de uma disputa entre formas diferentes de praticar ciência normal e são, precisamente, os paradigmas definidores dessas formas que estão em questão. Por isso, "cada grupo usa seu paradigma para argumentar na defesa daquele mesmo paradigma". No entanto, sustenta "a circularidade resultante não torna os argumentos errados nem ineficazes", pois o que tais argumentos visam obter não é uma demonstração de superioridade objetiva, mas sim uma persuasão em favor de uma nova perspectiva de prática científica que se abreinicialmente apenas como promessa - para aqueles que abraçarem o novo paradigma. Devido à circularidade, porém, o argumento "não pode ser tornado lógica nem probabilisticamente mandatório para aqueles que se recusam a entrar no círculo". E, para não deixar dúvidas, Kuhn postula: "as premissas e os valores compartilhados pelos dois partidos, em um debate sobre paradigmas, não são suficientemente extensivos para tanto" (grifo nosso). Por isso, "a escolha não é nem pode ser determinada meramente pelos procedimentos avaliativos característicos da ciência normal”. Vale lembrar que essa passagem vem logo antes de Kuhn defender (1970, p. 94) a tese (bastante plausível em si mesma) de que a escolha paradigmática não pode ser decidida pela lógica e pelo experimento, e logo após ele ter traçado (p. 93) o paralelo entre as revoluções científicas e as revoluções políticas, tendo observado que, nas últimas, na ausência de uma instância suprapartidária de arbitragem, os partidos envolvidos recorrem a técnicas de “persuasão de massas", incluindo a força.

Eis aqui, redigida com toda a clareza, a formulação de uma das formas de incomensurabilidade presentes em Kuhn, isto é, a variância dos critérios de escolha teórica. Esta, como veremos, soma-se às outras, a saber, as variâncias na agenda de problemas e nos padrões de solução - às quais voltaremos ainda nesta meditação -, e as variâncias de significado (a mais popular e extensamente discutida) e de exemplares, sobre as quais iremos falar adiante. Surge agora a ameaça de uma consequência efetivamente muito forte, até mesmo perversa. Se não houver algum mecanismo de interação e comunicação (intercâmbio de informação) entre as partes do sistema, capaz de permitir pelo menos o debate (ainda que não fixe o rumo nem determine o resultado), essas variâncias, se válidas, tornariam impossível a racionalidade das decisões científicas e da mudança científica, mesmo que se opere com uma concepção flexível de racionalidade.

A resposta de Laudan a esse argumento (1984, p. 95-6; 1996, p. 95) baseia-se em sua crítica ao modelo holista de mudança científica. Recairia sobre Kuhn o ônus de provar que a mudança científica não é gradual nem parcial, mas sim global, envolvendo simultaneamente teoria, ontologia, metodologia, axiologia, como acontece com os componentes das matrizes disciplinares kuhnianas. De fato, já na primeira edição de Estrutura, Kuhn havia escrito que "ao aprender um paradigma, o cientista adquire con- 
VALORES E incomensurabilidade: Meditações KuHNiANAS...

juntamente teoria, métodos e padrões, usualmente em uma mistura indissociável" (1970, p. 109). Ao contrário, para Laudan, é perfeitamente possível (e inclusive pode ser racional) uma variância seletiva e assíncrona, como, por exemplo, discordar acerca de teorias enquanto se está de acordo sobre a metodologia, discordar acerca de metodologia enquanto se está de acordo sobre a ontologia etc. Em um segundo momento da resposta, quando se trata de especificar um mecanismo de resolução das controvérsias (específicas e localizadas) acerca dos valores e da metodologia, Laudan remete-se ao seu modelo reticulacional (Laudan, 1984), que representa uma possibilidade de resolução racional de dissensos em ciência. A concepção de metodologia científica em termos de imperativos hipotéticos - que, embora possuam caráter contingente, não deixam de ter importe normativo, daí o nome de "naturalismo normativo" (Laudan, 1987) - vem somar-se ao modelo reticulacional, contribuindo para esclarecer a estrutura tanto do sistema cognitivo quanto do mecanismo de resolução desses conflitos. ${ }^{3} \mathrm{O}$ fato de que pode haver discordâncias acerca dos critérios de escolha teórica não precisa, portanto, acarretar necessariamente a indecidibilidade.

Pouco mais adiante em seu texto, Kuhn (1989b [1977]) sugere, de passagem, um mecanismo que, para o leitor atento, parece familiar: "A existência de um laço retroativo, mediante o qual a mudança teórica afeta os valores que conduzem a essa mudança, não torna o processo de decisão circular, prejudicial em qualquer sentido" (p. 4, grifo nosso). Trata-se, é claro, da relação não-hierárquica ou, dito de outro modo, do condicionamento recíproco que, segundo Laudan, vigora entre quaisquer componentes de um sistema de conhecimento científico, em particular, entre a axiologia científica e a teoria científica (cf. Laudan, 1984; Bezerra, 1999).

\subsection{A variÂncia DE PRoblemaS}

Os vários processos de variância científica estão na base das diferentes perspectivas sob as quais, na imagem kuhniana de ciência, pode-se considerar o fenômeno da incomensurabilidade. Prosseguindo em nossa discussão das formas de variância que se colocam no plano da metodologia - e que, acreditamos, nesse âmbito também podem ser desconstruídas - consideremos agora duas formas, ligadas, de acordo com Kuhn, à agenda de problemas científicos e aos critérios de solução. ${ }^{4}$

A um paradigma dominante, em regime de ciência normal, está associado um consenso acerca de quais problemas é mais importante resolver. Quando se tem uma

3 Sobre essa perspectiva, além das referências fundamentais de Laudan, ver também Bezerra (1999), Tambolo (2008). 4 Ambas são destacadas por Hoyningen-Huene (1993, p. 208-9) em seu mapeamento das formas de incomensurabilidade presentes no pensamento de Kuhn. 
proliferação de paradigmas alternativos, esse consenso desaparece. Segundo Kuhn, diferentes cientistas ou grupos de cientistas, que defendam paradigmas adversários, em geral estarão em desacordo quanto à agenda de problemas e quanto às prioridades relativas dos problemas. "Os proponentes de paradigmas adversários frequentemente discordarão acerca da lista de problemas que qualquer candidato a paradigma deve resolver" (1970, p. 14,8). Além disso, "os debates paradigmáticos sempre envolvem a questão: quais problemas é mais significativo solucionar? (...) essa questão de valores só pode ser respondida em termos de critérios que jazem fora da ciência normal" (1970, p. 110). A variância no nível da agenda de problemas acaba limitando o alcance de uma metodologia, em particular, uma metodologia de solução de problemas. Segundo a leitura feita por Laudan, essa tese de variância constitui o núcleo de mais um dos argumentos de Kuhn destinados a mostrar que as decisões interparadigmáticas são subdeterminadas pela metodologia (1984, p. 96 ss.; 1996, p. 95 ss.). A variância na agenda de problemas possibilita o aparecimento de situações do seguinte tipo: os defensores de paradigmas rivais asseveram, cada um por sua vez, que o seu respectivo paradigma é o melhor, porque soluciona precisamente aqueles problemas que eles consideram como os mais importantes. Os defensores de teorias rivais poderiam definir as respectivas listas de problemas de maneira "chauvinista" (por exemplo, simplesmente decretando que certos problemas são na realidade pseudoproblemas), de modo a obter como resultado altos índices de progressividade. E se cada um rejeitar a lista de problemas proposta pelo outro, estaria criado um impasse, em que cada um considera legítimo o seu próprio cálculo e ilegítimo o alheio. Considerações como essas haviam levado Kuhn a escrever, já no final da primeira edição de Estrutura, com respeito à escolha dos problemas, "que critério melhor poderia haver do que a decisão do grupo científico?" (1970, p. 170).

\subsection{A VARIÂNCIA DOS PADRÕES DE SOLUÇÃO AOS PROBLEMAS}

Se uma forma de variância diz respeito à agenda de problemas, outra diz respeito aos seus critérios de solução. Segundo Kuhn, no debate interparadigmático também desaparece o consenso quanto aos padrões ou critérios que determinam o que constitui uma solução aceitável para um problema. Quando há substituição paradigmática, ocorreria tanto uma "mudança resultante nos padrões e no campo de problemas", quanto "mudanças nos padrões que governam os problemas, conceitos e explicações permissíveis" (1970, p. 106). Em outras palavras, "quando mudam os paradigmas, usualmente há mudanças significativas nos critérios que determinam tanto a legitimidade dos problemas quanto a das soluções" (1970, p. 109). Mais especificamente, "assim como os problemas mudam, também frequentemente muda o padrão que distingue 
VALORES E incomensurabilidade: Meditações KuHNiANAS...

uma verdadeira solução científica de uma mera especulação metafísica, jogo de palavras ou manipulação matemática”. Precisamente por isso, conclui Kuhn, em enunciado já clássico, que "a tradição científica normal que emerge de uma revolução científica é não somente incompatível mas, com frequencia, efetivamente incomensurável com aquela que a precedeu" (1970, p. 103). A variância dos critérios de solução poderia fazer que, em um debate interteórico, os defensores de paradigmas rivais, apelando a diferentes conjuntos de critérios, fossem capazes de "provar" que os respectivos paradigmas são os melhores à luz dos seus próprios critérios. Nesse caso, cada um consideraria o valor de progressividade obtido pelo outro como ilusório, visto que nem todos os problemas ditos resolvidos foram "realmente" resolvidos (ou, no mínimo, não teriam sido "bem" resolvidos). Assim como no caso anterior, cada um poderia acusar o outro de parcialidade ou manipulação.

Tanto no caso da agenda de problemas como naquele dos padrões, nenhum debate bastaria para convencer cada lado das suas próprias fraquezas ou dos méritos do oponente. Como caracterizar a eventual resolução de tais discordâncias como sendo outra coisa que não um desenlace arbitrário? Em consequência, a decisão em favor de um paradigma e em detrimento de outro não seria, segundo Kuhn, uma decisão baseada exclusivamente em argumentos e parâmetros relacionados com a solução de problemas. "Para os cientistas, esses argumentos [baseados na capacidade solucionadora relativa dos competidores] são ordinariamente os mais significativos e persuasivos (...). Mas (...) eles não são nem individual nem coletivamente compulsórios” (1970, p. 155). Mais especificamente, a questão não seria solúvel por recurso a quaisquer medidas de solução de problemas. "[O]s debates paradigmáticos não são realmente acerca das capacidades relativas de resolução de problemas, embora por boas razões eles sejam usualmente colocados nesses termos (...). O indivíduo que abraça um novo paradigma em um estágio inicial deve fazê-lo frequentemente em desafio à evidência proporcionada pela solução de problemas". Finalmente, após esse postulado, vem o coup de grâce kuhniano. "Na verdade, ele deve ter fé em que o novo paradigma será bem-sucedido com os muitos e grandes problemas que o confrontam, sabendo somente que o velho paradigma falhou em alguns. Uma decisão desse tipo só pode ser tomada com base na fé" (Kuhn, 1970, p. 157-8, grifos nossos).

Assim, para o Kuhn de Estrutura, só teríamos problem-solving e racionalidade no que se refere à "ciência normal". Ao chegarmos à "ciência extraordinária", a problemsolving deixaria de ser decisiva, visto que seus recursos deixariam de ser suficientes para fundamentar decisões racionais. A decisão, então, teria que ser tomada "com base na fé". Trechos como esse de Kuhn suscitaram acalorados debates na filosofia da ciência das décadas de 1960, 1970 e 1980. E não sem razão. Retornaremos ao problema da radicalidade das afirmações de Kuhn logo adiante. 


\subsection{O ÂMBito METODOLÓGico}

Penso que o aspecto crucial a ter em mente para analisar criticamente os argumentos da variância de problemas e dos padrões de solução é que ambos dizem respeito ao plano metodológico do conhecimento. A escolha de problemas na ciência, e a atribuição de pesos a eles, não se dá em um vácuo, nem de maneira arbitrária, mas deve ser resultante de considerações metodológicas. Por outro lado, os padrões de solução aos problemas são indiscutivelmente elementos dotados de importância metodológica. Como salienta Laudan (1984, p. 96-101; 1996, p. 95-8), os argumentos da variância de problemas e de padrões de solução só parecem ameaçadores na medida em que se esquece de fazer uma distinção muito básica. Uma coisa, diz ele, é atribuir um peso elevado a um determinado problema por mera decisão arbitrária do cientista. Outra coisa, bem diferente, é fornecer as razões pelas quais se toma aquele problema como significativo e, possivelmente, significativo até mesmo para sustentar, durante a mudança paradigmática, a afirmação de que um paradigma é melhor do que outro. Quando se pergunta a um cientista "por que solucionar este problema é mais importante do que solucionar aquele?", não bastaria responder "porque estou mais interessado em resolver este do que aquele". Seria preciso, em vez disso, justificar esta ou aquela preferência com argumentos para mostrar que tal ou qual problema é mais significativo no sentido probatório. Nas palavras de Laudan, “a atribuição racional de qualquer grau particular de significado probatório deve basear-se na capacidade de mostrar que há bases metodológicas e epistêmicas para atribuir um certo grau de importância em vez de outro" (1984, p. 99; 1996, p. 97-8). Disso, ele conclui (na versão mais recente do texto): "uma vez que enxerguemos isso, torna-se claro que é possível, em princípio, avaliar o apoio empírico para cada teoria de uma maneira que não requer um compromisso prévio com um paradigma ou outro" (1996, p. 98). Fica exposto, portanto, o fato de que Kuhn não representa a situação de maneira completa. Como vimos, ele exclui completamente toda possibilidade de existirem mecanismos de arbitragem racional, trans-paradigmática, das discordâncias metodológicas e axiológicas, precisamente os mecanismos que são proporcionados pelo modelo reticulacional e pelo naturalismo normativo de Laudan. Por isso, Kuhn não implementa plenamente a ideia de problem-solving; na sua visão, a variância de problemas parece irredutível, quando, na realidade, far-se-ia necessário recorrer a um nível de análise mais profundo. 5

5 Laudan, em sua discussão, limita-se a considerar apenas as razões probatórias que dizem respeito ao teste propriamente empírico da teoria. Porém, pode-se imaginar a inclusão, nessa dinâmica, tanto das razões conceituais - já analisadas pelo próprio Laudan $(1984 ; 2011)$ - quanto das razões ligadas aos valores não-cognitivos, como os valores sociais, econômicos e políticos - e, nesse caso, seria necessário incorporar algum modelo que preveja mecanismo de interação entre as esferas cognitiva e social, como, por exemplo o de Lacey (2008), ou o modelo causal/simétrico (ou "programa forte") em sociologia da ciência. 
VAlores e incomensurabilidade: Meditações KuHNianas...

\section{Segunda meditação: incomensurabilidade}

A incomensurabilidade é, indubitavelmente, o conceito mais problemático e de difícil interpretação presente na filosofia da ciência de Kuhn. Não é exagero dizer que rios de tinta já correram acerca da caracterização ou da definição do conceito, acerca dos subtipos em que esse conceito pode se subdividir, acerca das teses que Kuhn teria formulado por seu intermédio, acerca das teses que o próprio Kuhn alega ter formulado com o seu concurso, acerca das mutações que essas teses sofrem ao longo do corpus de textos do autor, acerca das teses que podem ser formuladas em abstrato por meio de sua utilização e acerca de quais são as interpretações possíveis ou admissíveis de cada

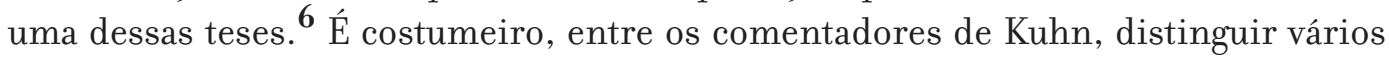
tipos diferentes de incomensurabilidade. Por exemplo, Bird (2011) distingue as incomensurabilidades metodológica, semântica e epistemológica, Hoyningen-Huene (1993, p. 208 ss.) distingue as incomensurabilidades de significado, de problemas e critérios de solução, e de "mundos". Também já se falou em incomensurabilidade taxonômica, linguística, ontológica, local, global, forte, fraca, parcial, moderada etc. Na meditação anterior, já iniciamos o mapeamento de variantes filosoficamente interessantes de incomensurabilidade, identificando três tipos (causadas pelas variâncias nos critérios de escolha teórica, nos problemas e nos padrões de solução), que se inscrevem sob a égide dos valores e da metodologia. Nesta meditação, prosseguimos com o inventário analisando mais dois tipos fundamentais: a incomensurabilidade semântica e aquela causada pela variância de exemplares.

\subsection{A incomensurabiLiddADE SEMÂNTICA}

Poderíamos dizer que a perspectiva "clássica" acerca da incomensurabilidade é aquela que a entende como sendo devida à variância de significado. Quando se passa de uma teoria (ou macroteoria) a outra, o significado dos termos mudaria de tal maneira que se torna impossível traduzir as asserções formuladas na linguagem da primeira para a linguagem da segunda teoria. Ou, por outra, torna-se impossível traduzir os enunciados de ambas as linguagens teóricas para uma mesma linguagem-objeto "neutra".7 $\mathrm{O}$ mesmo termo pode significar coisas completamente diferentes nas duas teorias.

6 De minha parte, destaco Hoyningen-Huene (1993, cap. 6, seção 6.3), Hoyningen-Huene e Sankey (2001), Sankey (1993), Guitarrari (2004), Balzer (1985), Dilworth (2008), Stegmüller (1981 [1979], cap. 11). Para um bom catálogo, referenciando parte significativa da enorme literatura existente a respeito do tema, ver Hoyningen-Huene (1993, p. 207, nota $5^{8}$ ).

7 A candidata natural seria uma suposta "linguagem observacional". A convicção de que não existe uma linguagem observacional "pura" ou "neutra" foi uma das motivações principais (juntamente com a análise histórica) que levaram Kuhn e Feyerabend a propor a tese da incomensurabilidade. 
O exemplo tradicionalmente citado é o do conceito de "massa", que significa coisas totalmente diversas na mecânica clássica e na mecânica relativística. ${ }^{\mathbf{8}}$ Não seria possível descrever ou analisar, a partir de uma das teorias, qualquer parte da outra. Diz-se, portanto, aproveitando a terminologia da geometria antiga, que as teorias são incomensuráveis. Segundo uma interpretação possível, os defensores de teorias incomensuráveis ficam, dessa forma, impedidos de estabelecer qualquer comunicação mútua. O corolário clássico é enunciado pelo próprio Kuhn: "precisamente por tratar-se de uma transição entre incomensuráveis, a transição entre paradigmas em competição não pode ser feita um passo de cada vez, forçada pela lógica e pela experiência neutra. Tal como a mudança de gestalt, ela deve ocorrer de uma vez (embora não necessariamente em um instante) ou não ocorrer nunca" (1970, p. 150).

O mais importante é que a tese da incomensurabilidade parece ter uma consequência fortíssima no nível metodológico, a saber, a impossibilidade de fazer-se qualquer comparação entre teorias diferentes, em particular, qualquer comparação dos seus respectivos méritos cognitivos. Segue-se (segundo a ortodoxia da incomensurabilidade) que seria impossível qualquer avaliação do desempenho de teorias rivais envolvidas em uma competição e, portanto, seria impossível decidir racionalmente por uma ou pela outra. O resultado, então, seria uma imagem de evolução do conhecimento caracterizada pelo relativismo cognitivo. O que poderia haver são "experiências de conversão" subjetivas que impelem o cientista a abandonar uma teoria e a aderir a outra. No limite, o que existiria é, quando muito, retórica e propaganda que visam aliciar cientistas em favor desta ou daquela teoria.

O trabalho de fazer uma reflexão filosófica sobre a incomensurabilidade é dificultado pelo fato de que, ao longo de Estrutura e dos textos posteriores, o uso que Kuhn faz do termo é metafórico, cambiante e em vários registros diferentes. Sankey (1993) e Hoyningen-Huene (1993, cap. 6, seção 6.3) fazem uma periodização tripartida para mapear a evolução do(s) conceito(s) de incomensurabilidade ao longo da obra de Kuhn. Eles identificam uma primeira fase, marcada pela primeira edição de Estrutura, com as primeiras formulações (frequentemente metafóricas) da noção (ou noções) de incomensurabilidade. Em uma segunda fase, tem-se a reelaboração da noção nos textos do final dos anos 1960 e início dos anos 1970, em resposta às reações críticas suscitadas pelo livro. Por fim, há as concepções da maturidade, já nos anos 1980.

No texto que é considerado o locus para a versão mais elaborada de sua análise do conceito, Kuhn (2006c [1983]) distingue a noção de tradução da noção de interpretação. Uma operação de tradução é aquela por meio da qual se produz um texto de chega-

8 Outros exemplos são a redefinição do conceito de "planeta" na revolução astronômica, e a redefinição do conceito de "movimento" na revolução científica. Ainda outro exemplo diz respeito ao conceito de oxigênio como "elemento", por contraste com as concepções próprias da química do flogisto e dos "princípios”. 
VAlores e incomensurabilidade: Meditações KuHNianas...

da equivalente ao texto de partida (ainda que possa não haver uma correspondência termo a termo). Para que a tradução seja possível, é preciso que o tradutor conheça a língua de partida e a língua de chegada, e ambas devem existir anteriormente ao processo de tradução. Por outro lado, a interpretação é um processo (análogo ao aprendizado da língua materna) pelo qual o intérprete (que pode conhecer apenas a língua de chegada e não fazer parte da comunidade de falantes da língua de partida) não traduz, mas sim procura aprender a língua de partida. Na interpretação, os conceitos não são adquiridos isoladamente, mas sim conjuntamente, em um todo interconectado e interdefinido. A interpretação, portanto, é a alternativa que resta naqueles casos em que uma mera paráfrase não seria satisfatória para restabelecer a comunicação. ${ }^{9}$ Kuhn reserva o termo "incomensurabilidade" para aquelas situações em que a tradução entre léxicos diferentes não é possível, mas a interpretação ainda permanece possível (2006c [1983], p. 55). A afirmação de que duas teorias são incomensuráveis expressa uma situação em que não é possível obter uma tradução sem resíduos ou perdas entre os léxicos. Porém, nesses casos, a comunicação ainda não estaria inviabilizada.

Neste ponto, é indispensável mencionar a conexão com Quine (2004 [1960]), que formula sua famosa noção de tradução radical, referida por Kuhn (cf. 2006a [1970], p. 203 ss.; 1970, Pós-escrito, p. 202) - que seria uma situação de tradução entre membros de comunidades linguísticas que nunca tiveram contato entre si, e cujas raízes histórico-culturais não se intersectaram em nenhum momento do passado - e a tese da indeterminação da referência, isto é, a impossibilidade de estabelecer, durante a tradução radical, a referência e o significado dos termos de maneira não ambígua. Por meio do já clássico experimento mental do "gavagai”, Quine mostra sucessivamente inúmeras tentativas frustradas de chegar a um manual de tradução completo entre as expressões de uma língua e as expressões da outra. Embora o argumento de Quine parecesse dar suporte a uma visão de incomensurabilidade como a de Kuhn da primeira fase, já não dá mais sustentação à noção reelaborada da terceira fase. De acordo com Kuhn (2006c [1983], p. 52-4), o equívoco fundamental de Quine é que a situação que ele analisa corresponde àquilo que Kuhn qualificaria como interpretação, porém o enfoque que ele dá a essa situação ainda é o da tradução.

A outra conexão inescapável, neste contexto, é com Donald Davidson (1984 [1974]), que dirigiu uma crítica contundente à noção de incomensurabilidade entre paradigmas ou, mais precisamente, nos termos de Davidson, ao "relativismo conceitual". O argumento de Davidson parte de uma equivalência entre as noções de "es-

9 É justo notar que, em textos kuhnianos da "fase de transição", como a seção 5 do Pós-escrito à segunda edição de Estrutura, e os parágrafos finais de (1989b [1977]), Kuhn já aponta, ainda que de maneira um tanto confusa, para os dois registros possíveis daquilo que ele chama de "persuasão", o registro da tradução e, para além deste, o da interpretação. 
quemas conceituais diferentes" e de "linguagens não mutuamente traduzíveis", e procura mostrar que não faz sentido falar nem em fracasso total de tradução nem em fracasso parcial. A ligação direta com Kuhn é proposta pelo próprio Davidson, ao postular que o termo kuhniano-feyerabendiano "incomensurável" é equivalente ao seu termo "não intertraduzível" (p. 190). Sem entrarmos nos detalhes do argumento, a conclusão de Davidson é que a noção de esquema conceitual é vazia. Não se pode dizer que duas pessoas tenham esquemas conceituais diferentes, nem tampouco que elas compartilhem o mesmo esquema. O fundamento dessa conclusão está na crítica que Davidson lança ao "dogma do dualismo" entre mundo e esquema conceitual (o "terceiro dogma do empirismo", como ele diz).

É surpreendente que tanto a análise de Quine - que parece trazer água para o moinho da incomensurabilidade - quanto a de Davidson - que parece secar essa mesma água - estribam em um pressuposto comum. Isso foi percebido por Ian Hacking (2009 [1982]). O pressuposto é que tanto os manuais de tradução quanto os esquemas conceituais têm seu foco primordialmente nos elementos que são (tidos como) verdadeiros (por exemplo, as proposições). É na equiparação das proposições verdadeiras que se baseia a noção usual de "correção de uma tradução". Sob esse ponto de vista, uma boa tradução precisaria, acima de tudo, preservar a verdade (truth-preserving). Logo, é essa noção que também está na base tanto da tese dos limites da tradução radical, de Quine, quanto da tese da inexistência de esquemas impossíveis de traduzir, de Davidson.

Aos esquemas conceituais criticados por Davidson, Hacking (2009 [1982]) contrapõe um conceito - o de "estilo de raciocínio" - que tem seu cerne, não mais na catalogação daquilo que é verdadeiro, mas sim naquilo que é verdadeiro-ou-falso, ou seja, que apresenta a possibilidade de ser verdadeiro (propriedade que é contingente, e pode mesmo não se realizar na prática). Os estilos de raciocínio, de acordo com Hacking, não são como esquemas conceituais que confrontam a realidade. A noção de estilo de raciocínio aproxima-se da noção de interpretação/aprendizado de um novo léxico (paradigma) de Kuhn, na medida em que, para compreender-se um estilo de raciocínio estranho (o exemplo dado por Hacking é o da alquimia de Paracelso), trata-se de aprender, em vez de traduzir. Escreve ele que "o que éverdadeiro-ou-falso em um modo de falar pode não fazer muito sentido em outro até que a pessoa tenha aprendido a raciocinar de um novo modo. (...) A tradução das verdades é irrelevante. A comunicação de modos de pensar é o que interessa" (2009 [1982], p. 192). Assim, as noções de estilos de raciocínio e de aprendizado (Hacking) permitem elucidar sob novo ângulo, respectivamente, as noções de paradigmas incomensuráveis e de interpretação (Kuhn). Os paradigmas incomensuráveis são mais do que esquemas intraduzíveis de maneira truth-preserving. Por isso, a identificação antes postulada por Davidson não se aplica a 


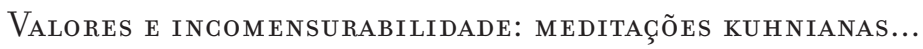

Kuhn, e o argumento do primeiro contra a noção de esquema conceitual não é decisivo contra a noção de paradigmas incomensuráveis.

Apesar de ter inicialmente ensaiado identificar um registro limitado ou local de incomensurabilidade, que afetaria apenas um subconjunto da rede conceitual, Kuhn logo admite que "não está claro, contudo, que a incomensurabilidade possa ser restrita a uma região localizada (...). É simplesmente implausível que alguns termos mudem de significado, quando transferidos para uma nova teoria, sem contaminar os termos transferidos conjuntamente" (2006c [1983], p. 51). Então, Kuhn se lança a um mapeamento de terreno, visando buscar onde se encontrariam os "invariantes de tradução" (p. 67-71), ele evita falar em "invariantes de significado". Quais seriam os aspectos cuja ausência indica que o mundo está estruturado de uma forma diferente, irredutível à anterior? Kuhn acredita que eles residam nas estruturas taxonômicas, isto é, nas estruturas pelas quais o mundo é categorizado e no bojo das quais se podem colocar as relações de similaridade e diferença. Não é senão nessas estruturas que uma tradução teria que buscar seus invariantes (caso existissem), de forma a estabelecer a comunicabilidade. Quando não for possível encontrar essa invariância de estrutura, a possibilidade de tradução é efetivamente bloqueada, pois os léxicos são fundamentalmente diferentes: "onde há uma diferença de estrutura, o mundo é diferente, a linguagem é privada, e a comunicação cessa até que uma das partes adquira a linguagem da outra" (p. 7o). Porém é somente no hipotético caso extremo, em que nem mesmo a interpretação pudesse dar acesso a essa taxonomia, que a comunicabilidade ficaria, finalmente, impossibilitada.

\subsection{INGOMENSURABILIDADE E GOMPARABILIDADE}

A defesa que Hoyningen-Huene (um intérprete declaradamente afinado com o pensamento de Kuhn) faz em seu livro de 1993 da visão de incomensurabilidade proposta pelo Kuhn da maturidade utiliza uma noção de "incomensurabilidade local". Cabe, porém, assinalar que Hoyningen-Huene (p. 219) entende essa "localidade" de maneira claramente diferente daquela que é considerada por Kuhn (2006c [1983]). Para Kuhn, a incomensurabilidade é local quando afeta apenas uma parte do aparato conceitual (isto é, "teórico" no sentido estrito) da teoria; para Hoyningen-Huene, ela é local quando não afeta a parte do sistema teórico relativa às aplicações ou predições. Acentua-se que, na explicação do conceito de incomensurabilidade que Kuhn elabora a partir dos anos 1980, ele deixa de recorrer, como antes fazia, à noção de uma linguagem de observação neutra como sendo a interface ou a ponte entre as duas teorias. Nos textos mais antigos, como a primeira edição de Estrutura, ainda era a inexistência dessa linguagem-pivô que caracterizava a incomensurabilidade. Todavia, nos textos mais re- 
centes, a marca da incomensurabilidade é a impossibilidade de mútua tradução entre duas linguagens dadas.

O aspecto central afirmado por Hoyningen-Huene (1993, p. 219) é que a incomensurabilidade não implica incomparabilidade, na medida em que se possa dizer que teorias incomensuráveis são dirigidas para o mesmo domínio de objetos. Embora esse domínio de objetos não possa ser acessado de nenhuma forma teoricamente neutra (pois diferentes léxicos originam diferentes domínios de objetos), a diferença entre os domínios não seria total (aqui entra a chamada incomensurabilidade local), e os "potenciais empíricos" das teorias poderiam ser comparados. O exemplo dado por Hoyningen-Huene é o da transição da astronomia ptolomaica para a copernicana (p. 220). Segundo ele, ainda que haja a incomensurabilidade (manifesta, por exemplo, na ressignificação do termo "planeta" etc.), persistem certos elementos, tais como as posições planetárias no firmamento, que podem ser diretamente comparados. "Embora os conceitos incomensuráveis possam ser centrais para ambas as teorias", escreve ele, "muitas das predições da teoria podem ser formuladas de maneira inteiramente comensurável" (p. 219-20). De acordo com Hoyningen-Huene, quando se passa da incomensurabilidade local a um genuíno aprendizado parcial, e do aprendizado parcial a um domínio pleno do novo léxico, novas possibilidades adicionais de comparação interteórica apresentam-se (p. 220-1). Assim, conclui ele, não se impõe a situação de que teorias incomensuráveis seriam necessariamente incomparáveis, nem que os episódios de mudança teórica haveriam de ser, por isso, forçosamente irracionais.

Ora, embora a observação de Hoyningen-Huene seja perspicaz, parece-me que não está aberto aos kuhnianos "ortodoxos" o caminho de dizer, como ele pretende, que a comparação possa recorrer a um "potencial empírico" invariante através da mudança teórica. Os defensores da received view, é claro, indubitavelmente subscreveriam essa tentativa, afirmando sem pestanejar, por exemplo, que a astronomia copernicana e a astronomia ptolomaica dizem respeito ao mesmo conjunto de dados da astronomia de posição. Essa saída - equivalente a recorrer, mais uma vez, a uma base empírica objetiva, precisamente aquilo cuja existência foi certa vez negada pelo próprio Kuhn - certamente não estaria aberta para o Kuhn da primeira edição de Estrutura, quando defendeu uma tese fortíssima de impregnação teórica e de não neutralidade da base empírica, por exemplo, no capítulo intitulado "As revoluções como mudanças de concepção de mundo”. Ali, entre muitas outras passagens relevantes, Kuhn escreve, por exemplo, após discutir o episódio que envolve Dalton, "os próprios dados haviam mudado" (1970, p. 135). Ademais, é crucial observar que Hoyningen-Huene teve a sorte (ou o cuidado) de selecionar um exemplo privilegiado (ptolemismo versus copernicanismo), o qual, aparentemente, apresenta um perfil epistêmico bastante favorável no que tange a identificar a relevância e o "foco" dos dados. Ainda assim, em geral, deve-se 
VALORES E incomensurabilidade: Meditações KuHNiANAS...

levantar o seguinte questionamento. Nos casos mais ricos e interessantes da ciência, como se poderá determinar quais dados são relevantes? E para qual parte do sistema? Em situações razoavelmente complexas e realísticas, certos dados poderão ser relevantes para avaliar a adequação empírica de uma teoria, mas outros dados diferentes poderão ser relevantes para outra. Ou o grau de relevância poderá ser diferente, e tudo isso determinado pelas diferenças no léxico e na taxonomia. Raramente se poderá ter, creio eu, em muitos casos típicos de mudança conceitual de grande envergadura na ciência, o mesmo grau de nitidez que parece apresentar-se no caso das posições planetárias.

\subsection{Kuhn e AS visões de mundo, ou “aVAnçAR Retrocedendo"}

São famosas as afirmações de Kuhn no sentido de que "os defensores de paradigmas rivais praticam seu ofício em mundos diferentes" e de que "após uma revolução, os cientistas respondem a um mundo diferente" (Kuhn, 1970, p. 111, 120, 150). Temos aqui a noção de paradigma como "mundo sociocognitivo" - a expressão bastante feliz é de Terry Shinn e Pascal Ragouet (2008, p. 49) - vindo somar-se às acepções do termo já explicitamente reconhecidas por Kuhn nos textos do final dos anos 1960 e início dos 1970, a saber, paradigma como realização científica exemplar e como constelação de compromissos compartilhados pela comunidade científica (depois reelaborada em termos de "matriz disciplinar").

Hoyningen-Huene faz um dedicado exercício de exegese kuhniana, tentando realizar uma tarefa muito difícil, ou seja, encontrar uma interpretação coerente para as afirmações de Kuhn sobre os "mundos". Primeiramente (1993, seção 2.1), ele faz um esforço - comovente, pode-se dizer - para elaborar uma leitura "kantiana" do Kuhn da primeira fase, girando em torno das ideias de "inacessibilidade do "mundo-emsi" ", somada à pluralidade e irredutibilidade dos "mundos-fenomênicos". Em seguida (seção 2.2), ele tenta encontrar coerência nas digressões algo obscuras de Kuhn (1989a [1974]), no sentido de que os cientistas de comunidades diferentes captariam "dados diferentes a partir dos mesmos estímulos" (Kuhn, 1989a [1974], p. 370-31, nota 18). Com isso, ele tenta (1993, seção 6.2) separar aquilo que Kuhn obstinadamente juntou, a saber, o discurso sobre "mudanças de mundo" e o discurso sobre "mudanças de visão de mundo".

Há um típico problema textual e temático no pensamento kuhniano que parece ser precisamente o seguinte. Propor uma tese que, na sua versão inicial, é radical e provocativa, para depois, por meio de reinterpretações que parecem recuos, enfraquecê-la até que ela se torne aceitável (ou inofensiva, dependendo da leitura), mas, com isso, ela parece também perder a sua razão de ser, pelo menos sob o ponto de vista do sistema kuhniano original. Via de regra, da forma como essa reinterpretação é formu- 
lada, a tese volta a aproximar-se dos pontos de vista mais tradicionais, previamente existentes. Esse problema aparece no discurso de Kuhn e dos kuhnianos sobre a incomensurabilidade e reaparece, por exemplo, no discurso sobre a "subestrutura da comunidade científica”, os "microparadigmas" e as "microrrevoluções”, e ainda no discurso sobre o papel dos valores e a subdeterminação metodológica das escolhas científicas. No caso há pouco mencionado, onde se recorre à ideia de estímulos perceptivos comuns, o que faz a reinterpretação proposta parecer um recuo é que Kuhn e seus seguidores parecem retornar a uma noção de base empírica objetiva e neutra.

Kuhn reiteradamente se queixa, em textos dos anos 1970 e 1980, de que teria sido mal compreendido. ${ }^{10}$ Como se sabe, ele recorre algumas vezes ao expediente retórico e irônico de traçar um contraste entre "certo autor chamado Kuhn", que redigiu a Estrutura e outros textos, e "um outro autor", também chamado "Kuhn", cujo pensamento foi discutido e, muitas vezes, distorcido pelos seus críticos (Kuhn, 2006a [1970], p. 156). Para citar apenas um exemplo desse tipo de "autorrevisionismo", Kuhn refere-se, no início de (2006c [1983], p. 51) àquilo que chama de "incomensurabilidade no sentido metafórico", sendo o sentido original do termo, "inexistência de medida comum", transformado em "inexistência de uma linguagem comum". E escreve, "a afirmação de que duas teorias são incomensuráveis é mais modesta do que supuseram muitos dos meus críticos". Ora, essa releitura de seu próprio papel no debate é, sem dúvida nenhuma, um revisionismo a posteriori, difícil de conciliar com as afirmações de Kuhn de que os cientistas adeptos de paradigmas diferentes fazem ciência em mundos diferentes. É perfeitamente lícito que Kuhn, na sua obra de maturidade, tenha passado a distinguir e delimitar diferentes registros ou formas de incomensurabilidade. Porém é certo que, na primeira edição de Estrutura, ele não fazia tais distinções, e anexava, ao discurso sobre a mudança conceitual, sem mais, o discurso sobre as mudanças de gestalt e as experiências de conversão, as mudanças de mundo e as decisões tomadas pela fé (como já foi documentado na meditação 1). Caberia, portanto, mais do que tentar ocultar esse deslocamento, e desautorizar seus críticos, admitir que seu pensamento evoluiu.

\subsection{A POSSIBILIDADE DE GOMPARABILIDADE MÉTRICA TRANSTEÓRICA}

De todo modo, o movimento argumentativo proposto por Hoyningen-Huene com relação à comparabilidade, como já foi dito aqui, baseia-se em uma intuição perspicaz, na medida em que procura distinguir duas regiões em uma teoria científica qualquer:

10 Kuhn fala, por exemplo, em “misconstructions" ([1970], p. 198-9), "mal-entendidos" e "interpretações erradas e deletérias” (2006a [1970], p. 192-3). 
VALORES E incomensurabilidade: Meditações KuHNiANAS...

uma que inclui os conceitos centrais e a taxonomia fundamental - e que pode ser incomensurável com a região correspondente de outra teoria - e outra região onde se formulam as predições, e que será comensurável com a região correspondente da outra teoria. Porém, pela falta de ferramentas apropriadas, que permitam uma análise "em alta resolução", essa tentativa esbarra em uma limitação da concepção de ciência de Kuhn, a saber, ele oferece uma repartição insuficiente, uma formulação demasiado amorfa, indistinta, da estrutura da base empírica da ciência e, assim, uma análise insuficientemente detalhada da adequação empírica. Um reflexo disso é a incapacidade de Kuhn e de Hoyningen-Huene de levar em conta a questão da relevância dos dados.

Um caminho para sair dessas dificuldades é possível, compatível com a ideia de Hoyningen-Huene, e ainda dentro de um espírito kuhniano, porém recolocando a questão em um novo contexto. Essa solução foi proposta por Laudan (2011, p. 198-204), com o objetivo de recolocar o problema da incomensurabilidade dentro de uma perspectiva de problem-solving. Segundo ele, é falso o pressuposto dos incomensurabilistas ortodoxos, de que todos os métodos de comparação interteórica sofrem de indecidibilidade por causa da impossibilidade de tradução para uma linguagem teoricamente neutra, pelo que não haveria qualquer possibilidade de avaliação comparativa objetiva das teorias e, portanto, de decisão inter-teórica racional. Laudan, ao contrário, sustenta que existem métodos para discutir-se objetivamente os méritos cognitivos das teorias, métodos que não dependem de quaisquer traduções diretas entre as teorias.

Mesmo sem dispor de um processo de tradução das teorias para uma linguagemobjeto invariante, argumenta Laudan, é possível falar sobre teorias diferentes que resolvem o mesmo problema, mesmo quando a caracterização específica do problema depende crucialmente de pressupostos teóricos. Os termos nos quais um problema é caracterizado dependem em geral de um espectro de pressupostos teóricos $\mathrm{T}_{1}, \mathrm{~T}_{2}, \ldots, \mathrm{T}_{\mathrm{n}}{ }^{\mathbf{1 1}}$ Se esses pressupostos constituem a(s) própria(s) teoria(s) que pretende(m) resolver o problema - mais precisamente, se o problema somente pode ser caracterizado em relação à linguagem e ao sistema conceitual das teorias que pretendem resolvê-lo - então, de fato, de nenhuma teoria rival seria possível dizer que soluciona o mesmo problema. Porém, na medida em que os pressupostos teóricos necessários para caracterizar o problema forem diferentes das teorias que visam resolvê-lo, é possível mostrar que teorias explicativas rivais podem dirigir-se ao mesmo problema.

Laudan não vai tão longe a ponto de afirmar que todos os problemas que uma teoria ou tradição de pesquisa procura solucionar podem ser caracterizados independentemente. Mas ele se aventura a afirmar que:

$11 \mathrm{O}$ texto de Laudan (2011, p. 200) traz “ $\mathrm{T}_{1}, \mathrm{~T}_{2}, \ldots, \mathrm{T}_{3}$ ”, devido, sem dúvida, a um erro tipográfico. 
com respeito a duas tradições de pesquisa (ou teorias) quaisquer em certo campo da ciência, há problemas conjuntos que podem ser formulados sem se pressupor nada que seja sintaticamente dependente das tradições de pesquisa específicas que estão sendo comparadas (Laudan, 2011, p. 201).12

Essa ideia crucial pode receber (ainda que de maneira independente) uma formulação precisa no contexto da metateoria estruturalista, como veremos a seguir. ${ }^{\mathbf{1} 3}$

\subsection{Kunn, A METATEORia ESTRUturalista E A incomensurabilidade}

Uma solução plena para o impasse kuhniano acerca da incomensurabilidade versus comparabilidade pode ser buscada com base na distinção "T-teórico/T-não teórico" para os conceitos científicos, nos moldes da metateoria estruturalista (doravante abreviadamente MTE), bem com nos conceitos estruturalistas de redução, incorporação e suplantação teórica. Para que essa construção possa ser formulada, é preciso trabalhar com certas noções fundamentais do aparato metateórico estruturalista. ${ }^{14}$

12 A tradução brasileira (Laudan, 2011, p. 201) consigna: "há problemas conjuntos que podem ser formulados de tal maneira que se pressuponha que nada é sintaticamente dependente das tradições de pesquisa específicas que estão sendo comparadas". Porém, o original em inglês (Laudan, 1977, p. 144) traz: "these are [sic] some joint problems which can be formulated so as to presuppose nothing which is sintacticaly dependent upon the specific research traditions being compared". (A locução "these are" é seguramente um erro de impressão, que deve ser lido "there are”.) O sentido é, então, aquele que cito no texto. Não se discute que possam existir, no sistema do conhecimento, itens que são sintaticamente dependentes das tradições. O importante énão ter que pressupor nenhum deles durante a comparação.

13 Laudan (2011, p. 202-4; 1976, parte 2) apresenta ainda uma generalização dessa ideia. Mesmo que não fosse possível a caracterização dos problemas de forma independente, ainda seria possível a comparação interteórica, bastando determinar a eficácia solucionadora de problemas de uma teoria (ou tradição de pesquisa) internamente à própria teoria, sem referência a nenhuma outra. Para isso, haveria que perguntar em que medida a teoria ampliou o número e importância dos problemas solucionados (dentre os problemas que colocou para si mesma) e se, nesse processo, também reduziu o número e importância das anomalias e problemas conceituais. Dessa forma, seria possível determinar a eficácia da teoria. Mais detalhes sobre as medidas de eficácia na solução de problemas encontram-se em Laudan (2011). Se isso fosse feito para todas as teorias (ou tradições de pesquisa) ativas em um dado momento, seria possível compor um ranking de progressividade das teorias. Essa forma de comparação é independente de quaisquer considerações relativas à comensurabilidade. Trata-se de comparar a performance das teorias, em vez de comparar as próprias teorias, ou mesmo suas aplicações. Antes, Laudan propunha delimitar um âmbito de comensurabilidade ao nível das aplicações ou dos problemas; aqui, trata-se de lidar com a incomensurabilidade em qualquer das suas formas (incluindo a mais forte imaginável - talvez apenas como hipótese - que implicaria, efetivamente, incomunicabilidade), e torná-la "sustentável”, por assim dizer. Tanto em um como em outro caso, a incomensurabilidade não precisa acarretar a incomparabilidade.

14. Não haveria aqui espaço para fazer uma exposição didática, nem tampouco uma que seja formalmente rigorosa. Para mais detalhes e formulações rigorosas, remetemos o(a) leitor(a) a algumas das inúmeras boas referências que apresentam de maneira sistemática a MTE, entre elas, Balzer, Moulines \& Sneed (1987), Balzer e Moulines (1996), Moulines (1982), Díez e Moulines (1999), Díez e Lorenzano (2002). 
VALORES E INGOMENSURABilidade: MEditações KUHNIANAS...

Na MTE, as teorias não são vistas como classes de enunciados, nem tampouco se identificam com as suas formulações linguísticas específicas. Em vez de sistemas axiomáticos interpretados, as teorias são vistas como classes de modelos, em certo sentido preciso no qual o termo "modelo" é entendido em sua acepção lógica ou metamatemática. O constituinte mínimo significativo de uma teoria científica não é mais o enunciado, mas sim o modelo. Ainda que se necessite de enunciados para formular (via de regra em linguagem conjuntista) as estruturas das quais existem modelos, o foco não está nesses enunciados, pois os modelos podem ser muito diversificados entre si. Por isso, as reconstruções estruturalistas de teorias específicas não devem ser consideradas "axiomatizações" no sentido tradicional do termo.

A menor unidade de estruturação teórica e de análise metacientífica sincrônica na MTE é o elemento teórico $\mathbf{T}$, que é uma estrutura formada por um núcleo $\mathbf{K}$, que expressa a parte formal da teoria, e por um conjunto de aplicações pretendidas I, que expressa a contraparte empírica e pragmática da teoria. Isto é indicado simbolicamente como $\mathbf{T}=\langle\mathbf{K}, \mathbf{I}\rangle$. O núcleo possui uma estrutura interna, cujos componentes principais (desconsideraremos alguns detalhes técnicos) são três classes de modelos: os modelos plenos M(T), os modelos potenciais Mp(T) e os modelos parciais Mpp(T). Os modelos potenciais são as estruturas que satisfazem os axiomas impróprios da teoria; eles contêm o arsenal conceitual básico da teoria ou, em outras palavras, delimitam o poder expressivo do formalismo. Os modelos plenos são aqueles modelos potenciais nos quais, além dos axiomas impróprios, também vale a "lei fundamental" da teoria. Os modelos parciais são versões dos modelos potenciais obtidos - informalmente falando - por "filtragem" ou "recorte" dos conceitos teóricos de $\mathbf{M p}$ (T).

Para que essa passagem dos modelos potenciais aos modelos parciais seja possível, é preciso dispor de uma maneira de distinguir aquilo que é próprio de uma teoria, isto é, o seu aparato conceitual específico, daquilo que não lhe é exclusivo, isto é, o seu aparato conceitual global. Essa propriedade é capturada pela noção estruturalista de teoricidade. A propriedade de "ser um termo teórico" não é mais vista como absoluta, mas é sempre relativa a uma teoria. Um termo é dito teórico em relação a $T$ se todos os procedimentos de determinação para esse conceito pressupõem a validade de T, e ele é não-teórico em relação a $T$, se existe pelo menos um procedimento de determinação que independe de T. A distinção "T-teórico/T-não teórico" é de caráter metodológico, e não se confunde com a distinção entre "observacional" e "não observacional" (que é de caráter epistemológico), e nem tampouco com a velha distinção que opunha "teórico" a "observacional”. A distinção entre T-teórico e T-não teórico, e assim a distinção entre M e Mpp, desempenha papel crucial na especificação da "base empírica" da teoria, e é nela também que se encontra a chave para equacionar-se o problema da incomensurabilidade, como veremos. 
O "recorte" dos termos T-teóricos, de modo a gerar os modelos parciais, é obtido formalmente por meio do chamado funtor de Ramsey, denotado por $\mathbf{r}(\mathbf{M}(\mathrm{T}))$, que está relacionado com o venerável conceito de "sentença de Ramsey", associado a uma teoria. Desse modo, na MTE, encontra-se o justo papel que pode ser desempenhado pela sentença de Ramsey. Ela não é empregada para "eliminar os termos teóricos", como certa vez se pensou (cf. Suppe, 1977, p. 32-3), mas sim para organizar a teoria, em particular, ela permite identificar quais são as suas subestruturas empiricas, que irão desempenhar um papel crucial no teste empírico da teoria.

Vale lembrar que o próprio Kuhn tece alguns comentários a respeito da possibilidade de entender a teoricidade (e a introdução de termos teóricos) em termos das sentenças de Ramsey (cf. Kuhn, 2006c [1983], p. 62-4). Kuhn percebe que as sentenças de Ramsey "não permitem, por si, bloquear um grande número de interpretações triviais" e, por isso, as considera inadequadas. Ele toca, assim, no ponto crucial, porém falta-lhe o restante do aparato para resolver o problema. De fato, é preciso mais do que as sentenças de Ramsey. A metateoria estruturalista mostra que elas precisam estar conectadas também ao aparato teórico, ou seja, aos modelos teóricos $\mathbf{M}$ e aos modelos potenciais Mp. Essa construção completa é que irá possibilitar, como veremos, uma solução ao problema da incomensurabilidade.

O outro componente constituinte de um elemento teórico, a classe de aplicações pretendidas I, conterá estruturas do tipo dos modelos parciais Mpp que conceitualizam precisamente aquelas porções da realidade às quais pretende-se que a teoria seja aplicável. Então, as aplicações pretendidas são uma subclasse das aplicações possíveis: em símbolos, I I I Mpp(T). O componente I possui um caráter intencional, contingente e seletivo. O conjunto de aplicações pretendidas não é simplesmente a classe das "consequências dedutivas testáveis" de um sistema axiomático, mas depende de um ato explícito dos cientistas de decidir aplicar aquele formalismo àquelas situações específicas. Se denotamos o conteúdo do elemento teórico $\mathbf{T}$ (ou seja, aqueles modelos parciais que podem ser aumentados com termos teóricos de modo a se tornarem modelos de T) por $\mathbf{C n}(\mathbf{T})$, então a asserção empírica da teoria é que I Î $\mathbf{C n}(\mathbf{T})$, isto é, ela afirma que as aplicações pretendidas estão entre os sistemas passíveis de serem descritos pelo formalismo teórico quando ele mobiliza seu aparato conceitual completo. Dito de outra forma, as aplicações pretendidas são "estruturas de dados" (modelos potenciais parciais) que podem ser estendidas, por adição de conceitos T-teóricos, de modo a se tornarem modelos plenos de $\mathbf{T}$.

A clássica tese da impregnação teórica da experiência - revisitada com tanto vigor retórico por Hanson, Kuhn e Feyerabend - pode ser agora reinterpretada no sentido de que os termos que comparecem na asserção empírica associada a uma teoria $\mathbf{T}$ inevitavelmente estarão sempre comprometidos com alguma(s) teoria(s) T'. Porém, o 
VALORES E INGOMENSURABilidade: MEditaÇões KuHNiANAS...

importante é que, na asserção empírica, estejam presentes apenas termos que sejam não teóricos em relação à própria teoria $\mathbf{T}$ que está sendo aplicada, isto é, não há objeção a que eles sejam "importados" (em certo sentido preciso) de outras teorias T' previamente disponíveis (nas quais eles poderão ser T'-teóricos). A asserção empírica pode ser formulada e ter relevância para avaliar a adequação empírica de uma teoria sem que seja necessário pressupor algo como uma linguagem observacional teoricamente neutra.

As teorias científicas mais articuladas possuem usualmente, além da lei fundamental, que deve ser cumprida por todos os modelos plenos de um elemento teórico, também um número variável de "leis especiais". Isso torna proveitoso definir outra estrutura sincrônica que é a de rede teórica, aqui denotada por $\mathbf{N}$, a qual se constitui a partir de um ou mais elementos teóricos básicos T. Na visão estruturalista, as redes teóricas são usualmente construídas por meio da relação de especialização, a qual pode ser definida de maneira precisa, sendo a ideia básica que um elemento teórico T' é uma especialização de outro elemento T quando as classes Mp e Mpp de ambos coincidem, mas as classes de modelos plenos e o conjunto de aplicações intencionais respeitam as condições de inclusão, a saber, M' Í M e I' Í I. Dito de outra forma, uma especialização afirma algo mais específico sobre um âmbito mais restrito. Assim, uma rede teórica representa a teoria científica em um crescendo de graus de especificidade. O conceito de asserção empírica de um elemento teórico pode ser generalizado, de maneira precisa, à rede teórica como um todo.

Para dar conta dos aspectos diacrônicos da ciência, introduz-se o conceito de evolução teórica, que, falando informalmente, corresponde ao desdobramento de uma rede teórica no tempo. Uma evolução teórica representa uma forma de mudança intrateórica, correspondendo aproximadamente à noção kuhniana de ciência normal. Uma evolução teórica é uma sequência (temporal) de $n$ redes teóricas $<\mathbf{N 1}, \mathbf{N 2}, \mathbf{N} 3, \ldots$, Nn> que têm em comum um núcleo básico Ko, o qual permanece invariante ao longo da evolução, sendo o mesmo para todas as redes Ni que a compõem. Ademais, as classes de aplicações pretendidas Ioi dos elementos teóricos básicos de todas as redes possuem uma interseção não vazia, que é dita a classe de aplicações paradigmáticas Ip da evolução. É importante apreciar o fato de que, sob a perspectiva da MTE, a noção de paradigma surge de maneira extremamente natural "de dentro" do formalismo, por assim dizer. Também é sugestivo o fato de que o paradigma é uma noção cuja formulação se torna relevante precisamente no momento em que se passa do registro sincrônico ao diacrônico ou dinâmico. O próprio Kuhn fez uma apreciação positiva da reinterpretação de algumas de suas ideias efetuada segundo a perspectiva da MTE, nos anos 1970 (Kuhn, 2006b [1976], cap. 7). A noção de classe de aplicações paradigmáticas será importante quando discutirmos mais adiante a incomensurabilidade por variância de exemplares. 
A contribuição da MTE para a análise da incomensurabilidade parte do fato de que essa perspectiva permite enfim compreender aquelas situações em que duas teorias possuem diferentes conceitos teóricos e, portanto, diferentes modelos potenciais Mp, mas ainda assim possuem os mesmos conceitos não teóricos e, portanto, os mesmos modelos parciais Mpp. ${ }^{15}$ Para estabelecer a comunicabilidade transteórica, não é possível basear-se em uma "mera tradução", pois os aparatos conceituais são efetivamente de tipos distintos. A divergência quanto aos conceitos teóricos pode ser interpretada como expressando a intuição de Kuhn de que as "estruturas taxonômicas" das duas teorias são diferentes. Assim, as teorias poderiam ser comparáveis ao mesmo tempo que são incomensuráveis, tal como sugeriam Hoyningen-Huene por meio de sua noção de "potencial empírico" e Laudan com seus problemas independentemente caracterizados. Ressalte-se que isso de maneira alguma significa um recuo em direção a algo como uma "base empírica neutra", posto que os modelos parciais descrevem uma experiênciajá estruturada, sendo constituídos por termos que, embora não sejam T-teóricos, podem ser T' -teóricos em relação a outras teorias. ${ }^{\mathbf{1 6}}$

Consideremos a noção (diacrônica) de incorporação de teorias sem incomensurabilidade (cf. Díez \& Moulines, 1999, cap. 13, seção 4; Moulines, 2011, seções 3.3, 5.3). Ela está baseada na relação (sincrônica) de redução. A noção estruturalista de redução entre duas teorias $\mathrm{T}$ (a teoria reduzida) e $\mathrm{T}^{*}$ (a teoria redutora), que pode ser generalizada para o caso das redes teóricas, envolve uma relação r efetivamente computável que, falando aqui em termos informais, ${ }^{17}$ expressa o fato de que:

(a) existe uma correspondência entre os aparatos conceituais (modelos potenciais) de T e de $\mathrm{T}^{*}$;

(b) as aplicações bem sucedidas de $\mathrm{T}$ podem ser reinterpretadas (pelo menos de forma aproximativa $)^{\mathbf{1 8}}$ como aplicações bem sucedidas de $\mathrm{T}^{*}$, isto é, pode-se dizer que ambas as teorias aplicam-se às "mesmas porções" do mundo empírico;

(c) as leis de $\mathrm{T}$ podem ser derivadas (pelo menos aproximadamente) das leis de $T^{*}$.

15 Ver Lorenzano (2008) para um estudo de caso envolvendo uma situação precisamente desse tipo no contexto da genética clássica, e Caamaño (2009) para um exemplo disso na transição da teoria do flogisto para a teoria do oxigênio. 16 Para uma discussão das características dos "modelos de dados" que aqui são os modelos parciais ver Bezerra (2011, seção 1).

17 Não seria possível fazer aqui mais do que uma narrativa informal, devido à extrema complexidade formal da análise estruturalista de redução. Para os detalhes técnicos, ver Balzer, Moulines e Sneed (1987, cap. 6). Para uma discussão mais acessível, ver Díez e Moulines (1999, cap. 11, seção 3, cap. 13, seção 4).

18 Vale ressaltar quer a noção de aproximação - de resto, notoriamente tão difícil de analisar filosoficamente recebe uma formulação rigorosa na perspectiva estruturalista: cf. Balzer, Moulines \& Sneed, 1987, cap. 7 . 
VALORES E Incomensurabilidade: MEditações KuHNiANAS...

Uma rede $\mathrm{N}$ será dita incorporável em uma rede $\mathrm{N}^{*}$ quando existir uma relação de redução tal que os modelos potenciais do elemento básico $\mathrm{T}_{0}$ de $\mathrm{N}$ possam ser traduzidos em modelos potenciais de $\mathrm{N}^{*}$, as leis fundamentais de $\mathrm{T}_{\circ}$ possam ser deduzidas das leis fundamentais de $\mathrm{N}^{*}$, e todas as aplicações bem-sucedidas de $\mathrm{T}_{\circ}$ estejam incluídas dentro da r-tradução das aplicações bem-sucedidas de $N^{*} .{ }^{19}$ Moulines (2011, p. 24) observa que é razoável supor que os fenômenos diacrônicos da evolução teórica e da incorporação teórica possam ser vistos como manifestações de uma situação mais geral, que poderia ser chamada de "trânsito comensurável" entre teorias.

As definições estruturalistas de redução e de incorporação parecem pressupor a retenção tanto das aplicações intencionais bem-sucedidas (o conteúdo empírico) quanto das leis teóricas (o conteúdo teórico). Nesse sentido, elas pareceriam implicar uma visão cumulativa de desenvolvimento científico, sem levar em conta a possibilidade de perdas durante a mudança teórica. Isso pareceria colocar uma restrição demasiado forte sobre o processo. No caso das chamadas "perdas epistêmicas" (cf. Laudan, 1976, parte 1; 2011, p. 205-10; 1996, cap. 6), essa restrição não seria satisfeita. Uma possibilidade, então, seria exigir meramente que "quase todas" as aplicações bem-sucedidas, ou uma parte considerável delas, fossem preservadas. Alguns autores estruturalistas, embora estejam conscientes do problema, mostram-se reticentes em adotar essa medida, manifestando dúvidas sobre se tais perdas são tão prováveis ou historicamente presentes quanto às vezes se pensa, e também sobre a sua magnitude, isto é, se as perdas não seriam numericamente insignificantes em comparação com os êxitos (cf. Díez \& Moulines, 1999, p. 455; Moulines, 2011, p. 25, nota 8).

A suplantação de teorias com incomensurabilidade (cf. Díez \& Moulines, 1999, cap. 13, seção 5 ; Moulines, 2011, seções 3.4, 7) está associada àquelas situações em que não se pode definir (ou não é efetivamente computável) a relação r entre os modelos potenciais, nem se pode derivar as leis da teoria $\mathrm{T}$ a partir das leis de T*. Nisso reside, pelo ângulo da leitura estruturalista, a essência da noção de incomensurabilidade. Porém, o ponto crucial a ressaltar é que isso não impede que as aplicações (que são modelos parciais) possam ser postos em correspondência entre si por meio de uma relação mais restrita, denotada $r_{e}$, definida não mais entre os modelos potenciais, mas sim entre os modelos parciais. Desse modo, a incomensurabilidade não implica incomparabilidade, pois, por exemplo, é possível formular a ideia de que a teoria $\mathrm{T}^{*}$ dá conta das "anomalias" de T.

19 Note-se que a incorporação de uma rede $\mathrm{N}$ a outra rede $\mathrm{N}^{*}$ envolve fundamentalmente apenas o elemento teórico básico T。da rede incorporada. Cf. Díez \& Moulines, 1999, p. $45^{3 .}$ 


\subsection{A VARIÂNGIA DE EXEMPLARES}

Consideramos, até aqui, quatro diferentes formas de incomensurabilidade de tipo kuhniano: uma gerada pela variância de significado (a incomensurabilidade semântica, léxica ou taxonômica), aquela devida à variância dos critérios de escolha (valores), e aquelas decorrentes da variância de problemas e da variância de padrões de solução. Foram analisados os seus desdobramentos, explorados os seus respectivos limites e também propostas soluções às dificuldades por elas suscitadas. No entanto, se fizermos um exercício de pensar em termos estritamente kuhnianos, a incomensurabilidade semântica e a incomensurabilidade de problemas parecem ser, na realidade, consequências de outra forma de variância, mais profunda, que resta analisar: a variância de exemplares.

Os exemplares são, segundo Kuhn, os elementos do sistema conceitual científico que permitem a modelagem das soluções para os enigmas e também permitem atribuir significado aos conceitos e enunciados. Os enigmas são solucionados mais com recurso ao conjunto de exemplares compartilhados pela comunidade científica do que por aplicação ab initio do formalismo na sua forma mais geral (generalizações simbólicas). É por comparação com esse conjunto de aplicações já arquetípicas, consolidadas, da teoria (ou paradigma, ou matriz disciplinar) que os cientistas conseguem discernir as semelhanças, as possibilidades e os caminhos de solução para seus problemas. Mas os exemplares fazem mais do que isso. Eles, na verdade, realizam duas funções (logo adiante tratarei de uma terceira). Eles permitem ao cientista: (1) identificar o estatuto problemático, isto é, reconhecer um problema enquanto tal; (2) reconhecer um enigma genuíno, isto é, um problema que seja (supostamente) solúvel pelo paradigma enquanto tal. Por isso, pode-se dizer que os exemplares são de certa maneira elementos constitutivos dos quebra-cabeças (problemas) científicos.

Ora, na visão kuhniana os exemplares pertencem a uma dimensão pré-linguística do paradigma que, na prática científica, existe de forma tácita ou implícita. Eles não são formalizados, e são "adquiridos" (a expressão é kuhniana) de forma não declarativa, não explicitamente, mas sim pelo uso. O cientista gradualmente aprende a reconhecer semelhanças entre os seus problemas e os exemplares do seu repertório. Essas relações de semelhança são extremamente complexas e, segundo Kuhn, não podem ser expressas explicitamente de forma completa. Por isso, pode-se dizer que está em jogo aqui um tipo de "similaridade inefável" (a expressão é de Luiz Henrique Lopes dos Santos), pré-linguística.

Finalmente, na visão kuhniana, os exemplares são altamente específicos para cada matriz disciplinar. Pode-se dizer mesmo que eles conferem identidade à matriz. 
VALORES E incomensurabilidade: Meditações KuHNiANAS...

Mudando-se os exemplares, passa-se a ter efetivamente uma nova tradição científica, e vice-versa. Portanto, entre diferentes paradigmas instaura-se uma variância radical de exemplares. Como são os exemplares que permitem individuar na prática os problemas, temos como resultado que cada tradição científica (paradigma, matriz disciplinar etc.) possuirá sua própria concepção do que venha a ser um problema genuíno, um problema solúvel, um problema bem resolvido etc. Essa divergência, por residir em uma dimensão pré-linguística, não pode ser explicitada nem analisada por completo, nem tampouco resolvida por debate e argumento. Pareceria que fica comprometida, de maneira fatal, a própria possibilidade de uma teoria geral (trans-paradigmaticamente válida) dos problemas científicos.

$\mathrm{Na}$ realidade, a variância de exemplares acaba sendo ainda mais destrutiva do que isso, em virtude de uma terceira função que é desempenhada pelos exemplares, a saber: (3) é como efeito do processo de reconhecer similaridades entre problemas inéditos e problemas exemplares preexistentes que emerge e é estabelecido o significado dos conceitos científicos, em um registro pragmático. Os exemplares são, assim, o dispositivo que permite dar uma interpretação às generalizações simbólicas. Ora, se isso é assim, em uma mudança paradigmática, os significados dos termos não mudam por fiat, por convenção nem por decisão arbitrária, mas sim porque o componente mais central e intrínseco do paradigma é transformado. Assim, a variância de exemplares seria, em uma imagem de ciência de tipo kuhniano, a mais fundamental, na medida que embasaria tanto a variância de problemas quanto a variância de significado e, nesse processo, originaria a forma mais radical de incomensurabilidade.

Será a variância radical de exemplares uma forma irredutível e inescapável de incomensurabilidade? Terá ela consequências efetivamente irracionalistas? Não obstante o fato de a análise dos parágrafos precedentes ser um desdobramento direto das ideias kuhnianas, cabe apontar um caminho de solução, que se apóia na perspectiva estruturalista. Na MTE, como vimos, o lugar dos exemplares é redefinido. Eles fazem parte, não mais da teoria no sentido sincrônico (o elemento teórico ou a rede teórica), mas sim de uma estrutura diacrônica, a evolução teórica. Nesse registro, os exemplares desempenham ainda um papel regulador, como subconjunto especial das aplicações pretendidas, porém não mais constituem uma condição de possibilidade da prática científica (como queria Kuhn). Os exemplares não exercem uma influência global a ponto de gerar incomensurabilidades, as quais, na visão estruturalista, encontram-se perfeitamente delimitadas. 


\section{Conclusão}

Após o percurso traçado nas meditações acima, constata-se que os principais entraves no caminho da formulação de uma imagem coerente da dinâmica da ciência, em uma chave pós-kuhniana, podem ser removidos. No que se refere à doutrina kuhniana sobre o papel dos valores na ciência, o enfoque reticulacional laudaniano tem êxito em desarmar os argumentos referentes à (suposta) ambiguidade e inconsistência dos critérios de escolha teórica. $\mathrm{O}$ impacto das diferentes formas de variância radical (de critérios de escolha, de problemas, de padrões de solução) também se vê drasticamente atenuado, em vista da possibilidade de instaurar mecanismos de tipo laudaniano para a resolução das controvérsias interparadigmáticas. Além disso, a intuição de Kuhn no sentido de que os critérios funcionam como valores esbarra em uma limitação importante, a saber, o fato de que ele não especifica, de maneira precisa, um mecanismo para a interação entre valores e conhecimento científico. Mecanismos gerais e bem definidos nesse sentido foram especificados, de maneira mais satisfatória, por Lacey (2008) e Laudan (1984; 1987).

Quanto à incomensurabilidade semântica, dada a reformulação do conceito pelo próprio Kuhn da maturidade, vemos que Hoyningen-Huene e Laudan conseguem vislumbrar - o primeiro de maneira ainda imprecisa, o segundo de maneira precisa, porém informal - a noção crucial que, ao receber uma formulação rigorosa no contexto da metateoria estruturalista, permite solucionar o impasse. Graças à noção estruturalista de teoricidade, e à distinção entre modelos potenciais e modelos parciais, constata-se que, mesmo em presença de variâncias no aparato conceitual (incomensurabilidade léxica-taxonômica), é possível resgatar a comensurabilidade ao nível das aplicações (problemas) intencionais e, portanto, a comparabilidade. A releitura estruturalista também permite minimizar o impacto da variância de exemplares. Finalmente, de todo modo, a metáfora kuhniana das "mudanças de (visão de) mundo", apesar de sugestiva, não logra capturar uma noção filosoficamente sistemática nem heuristicamente fértil.

Dessa forma, a análise realizada nestas duas meditações mostra que o alcance da incomensurabilidade vê-se drasticamente limitado em relação às pretensões originais de Kuhn, e suas implicações perversas (em particular, irracionalistas) são evitadas. É importante ressaltar ainda um outro ganho substancial que a análise aqui realizada possibilita no plano metacientífico. Se a visão kuhniana sobre o colapso da problem-solving e a variância radical de valores fosse válida, isso comprometeria a própria possibilidade de obtenção de uma imagem genuinamente dinâmica da ciência, uma vez que dois importantes fatores com eficácia cognitiva causal - dois propulsores da 
evolução do conhecimento científico, podemos dizer - estariam drasticamente bloqueados. Assim, a imagem kuhniana de ciência seria reduzida a uma cinemática descritiva da ciência, na qual não haveria possibilidade de perscrutar as razões pelas quais as mudanças conceituais e as escolhas científicas ocorrem da maneira pela qual ocorrem. Por outro lado, na medida em que se propõem mecanismos para a atuação plena desses fatores, o aspecto dinâmico é reabilitado.

Kuhn é, por definição, apenas o primeiro dos “kuhnianos”. Há problemas que ele logra enxergar e formular, nos quais, entretanto, deixa em aberto ou para os quais não oferece uma solução satisfatória. Kuhn abriu caminhos: algumas de suas intuições são perspicazes, porém os recursos próprios de sua imagem de ciência revelam-se muitas vezes insuficientes, insatisfatórios, para tratar os problemas do progresso e da racionalidade. Para isso, faz-se preciso mobilizar aparatos analíticos mais sofisticados. De todo modo, seja por afinidade, seja por oposição, ele colocou para os que vieram depois dele problemas, rumos e dilemas. A filosofia da ciência é diferente após a sua obra. Daí, acreditamos, a justeza de aplicar a $A$ estrutura das revoluções científicas, ao seu autor e a sua obra, a epígrafe (originalmente aplicada por ele a Copérnico e ao De revolutionibus), com a qual iniciamos este texto.๑

Agradecimentos. No curso de duas décadas e meia, beneficiei-me muito de discussões com várias pessoas acerca de aspectos do pensamento de Thomas Kuhn. Mesmo correndo o risco de ser traído pela memória, não posso deixar de aproveitar a oportunidade para agradecer especialmente a José Raimundo Novaes Chiappin, Steve Fuller, Robinson Guitarrari, Hugh Lacey, Larry Laudan, Zeljko Loparic, Pablo Lorenzano, Pablo Mariconda, Caetano Plastino, Luiz Henrique Lopes dos Santos, Joseph Sneed, Antônio Augusto Passos Videira, Alberto Villani e João Zanetic. Agradeço também a meus alunos de graduação e pós-graduação na Faculdade de São Bento e na Universidade Federal do ABC. Partes deste artigo resultam de pesquisas financiadas pela FAPESP e pelo CNPq.

Valter Alnis BezerRA Professor Doutor do Centro de Ciências Naturais e Humanas, Universidade Federal do ABC; Pesquisador Colaborador do Projeto Temático 2011/51614-3,

"Gênese e significado da tecnociência", Fundação de Amparo a Pesquisa de São Paulo, Instituto de Estudos Avançados, Universidade de São Paulo, Brasil. valter.bezerra@ufabc.edu.br 


\begin{abstract}
In this paper, two themes that figure outstandingly in the Kuhnian image of science are brought together, put into perspective, and re-interpreted: (1) the role of values in science and their relation with the issue of methodological underdetermination; (2) incommensurability and its dilemmas. Kuhn's theses concerning these themes are re-evaluated, how they unfold is critically discussed, and certain re-interpretations and reformulations are proposed. This is done according to two metascientific perspectives: Laudan's historiographic-metamethodological view (both in its problem-solving and reticulational variants), and the structuralist metatheory pioneered by Balzer, Moulines and Sneed. In this way, it is shown that the main difficulties inherent in the Kuhnian treatment of these questions can be removed, while at the same time being still possible to keep the most interesting features, as well as Kuhn's most insightful intuitions, concerning these issues.
\end{abstract}

KeYwords $・$ Kuhn. Incommensurability. Laudan. Structuralist metatheory. Values. Methodology. Scientific rationality.

\title{
REFERÊNGIAS BIBLIOGRÁFIGAS
}

BALZER, W. Incommensurability, reduction, and translation. Erkenntnis, 23, p. 255-67, 1985 .

Balzer, W. \& Moulines, C. U. (Ed.). Structuralist theory of science: focal issues, new results. Berlin: Walter de Gruyter, 1996.

Balzer, W.; Moulines, C. U. \& Sneed, J. D. An architectonic for science: the structuralist program. Dordrecht: D. Reidel, 1987 .

Bezerra, V. A. Problemas e seus problemas - a estrutura e a dinâmica da ciência vistas sob o enfoque de solução de problemas. São Paulo, 1994. Dissertação (Mestrado em Filosofia). Faculdade de Filosofia, Letras e Ciências Humanas, Universidade de São Paulo.

. Estruturas em busca do equilíbrio - o lugar da metametodologia e o papel da coerência no modelo reticulado de racionalidade científica. São Paulo, 1999. Tese (Doutorado em Filosofia). Faculdade de Filosofia, Letras e Ciências Humanas, Universidade de São Paulo.

. Estruturas conceituais e estratégias de investigação: modelos representacionais e instanciais, analogias e correspondência. Scientiae Studia, 9, 3, p. 585-609, 2011.

Bird, A. Thomas Kuhn. In: Zalta, E. N. (Ed.). Stanford encyclopedia of philosophy-Winter 2011 Edition. Stanford, CA: Metaphysics Research Lab, 2011. Disponível em: <http://plato.stanford.edu/archives/ win2011/entries/thomas-kuhn/> Acesso em: 13 jun. 2012.

CAamaño, M. A structural analysis of the phlogiston case. Erkenntnis, 70, p. 331-64, 2009.

Davidson, D. On the very idea of a conceptual scheme. In: __. Inquiries into truth and interpretation. Oxford: Clarendon Press, 1984, [1974]. p. 183-98.

Díez, J. A. \& Lorenzano, P. La concepción estructuralista en el contexto de la filosofía de la ciencia del siglo xx. In:___. (Ed.). Desarrollos actuales de la metateoría estructuralista: problemas y discusiones. Bernal: Universidad Nacional de Quilmes, 2002. p. 13- $7^{8 .}$

(Ed.). Desarrollos actuales de la metateoría estructuralista: problemas y discusiones. Bernal: Universidad Nacional de Quilmes, 2002.

Díez, J. A. \& Moulines, C. U. Fundamentos de filosofía de la ciencia. 2. ed. Barcelona: Ariel, 1999.

DiLwortн, C. C. Scientific progress: a study concerning the nature of the relation between successive scientific theories. 4. ed. Berlin: Springer, 2008. 
VALORES E INGOMENSURABilidade: MEditações KUHNIANAS...

Gibson Júnior, R. F. (Ed.). Quintessence: basic readings from the philosophy of W. V. Quine. Cambridge, Mass./ London: Belknap Press, 2004.

GUITARRARI, R. Incomensurabilidade e racionalidade científica em Thomas Kuhn: uma análise do relativismo epistemológico. São Paulo, 2004. Tese (Doutorado em Filosofia). Faculdade de Filosofia, Letras e Ciências Humanas, Universidade de São Paulo.

HACKING, I. Linguagem, verdade e razão. In: . Ontologia histórica. São Leopoldo, RS: Editora Unisinos, 2009 [1982]. p. 179-98.

Hoyningen-Huene, P. Reconstructing scientific revolutions: Thomas S. Kuhn's philosophy of science. Chicago/ London: University of Chicago Press, $199^{3}$.

Hoyningen-Huene, P. \& Sankey, H. (Ed.). Incommensurability and related matters. Dordrecht: Kluwer, 2001.

Kunn, T. S. The structure of scientific revolutions. 2. ed. Chicago: University of Chicago Press, 1970. Reconsiderações acerca dos paradigmas. In:

[1974]. p. 353-82.

. Objetividade, juízo de valor e escolha teórica. In: A tensão essencial. Lisboa: Edições 70, 1989a

[1977]. p. 383-4,05.

. A revolução copernicana. Tradução M. C. Fontes. Lisboa: Edições 7๐, 2002.

. Reflexões sobre meus críticos. In: . O caminho desde a estrutura: ensaios filosóficos, 1970-1993.

São Paulo: Editora da Unesp, 2006a [1970]. p. 155-216.

. Mudança de teoria como mudança de estrutura: comentários sobre o formalismo de Sneed. In: . O caminho desde a estrutura: ensaios filosóficos, 1970-1993. São Paulo: Editora da Unesp, 2006b [1976]. p. 217-40.

. Comensurabilidade, comparabilidade, comunicabilidade. In: O caminho desde a Estrutura: ensaios filosóficos, 1970-1993. São Paulo: Editora da Unesp, 2006c [1983]. p. 47-76.

Lacey, H. Valores e atividade científica I. São Paulo: Editora 34/Scientiae Studia, 2008.

Laudan, L. Two dogmas of methodology. Philosophy of Science, 4,3, p. 585-97, 1976. Progress and its problems: towards a theory of scientific growth. Berkeley/London: University of California Press, 1977 .

Science and values - the aims of science and their role in scientific debate. Berkeley: University of California Press, 1984.

. Kuhn's critique of methodology. In: Pitr, J. C. (Ed.). Change and progress in modern science. Dordrecht: D. Reidel, 1985 - p. 283-99.

. Progress or rationality? The prospects for normative naturalism. American Philosophical Quarterly, 24 , p. 19-31, 1987 .

. Beyond positivism and relativism - theory, method and evidence. Boulder: Westview Press, 1996.

. O progresso e seus problemas: rumo a uma teoria do crescimento científico. São Paulo: Editora da Unesp, 2011.

Lorenzano, P. Inconmensurabilidad teórica y comparabilidad empírica: el caso de la genética clásica. Análisis Filosófico, 28, 2, p. 239-79, 2008.

Moulines, G. U. Exploraciones metacientificas. Madrid: Alianza Editorial, 1982. Cuatro tipos de desarrollo teórico en las ciencias empíricas. Metatheoria, 1, 2, p. 11-27, 2011.

Pitr, J. C. (Ed.). Change and progress in modern science. Dordrecht: D. Reidel, 1985.

Quine, W. V. Translation and meaning. In: Gibson Júnior, R. F. (Ed.). Quintessence: basic readings from the philosophy of W. V. Quine. Cambridge, Mass./London: Belknap Press, 2004 [1960]. p. 119-68.

SANKey, H. Kuhn's changing concept of incommensurability. British Journal for the Philosophy of Science, 44, 4, p. 759-74, $199^{3}$. 
Shinn, T. \& Ragouet, P. Controvérsias sobre a ciência: por uma sociologia transversalista da atividade científica. Tradução P. R. Mariconda \& S. G. Garcia. São Paulo: Associação Filosófica Scientiae Studia/Editora $34,2008$.

Stegmüller, W. La concepción estructuralista de las teorías: un posible análogo para la ciencia física del programa de Bourbaki. Madrid: Alianza Editorial, 1981 [1979].

Suppe, F. The search for philosophic understanding of scientific theories. In: SupPE, F. (Ed.). The structure of scientific theories. 2. ed. Urbana/Illinois: University of Illinois Press, 1977. p. 1-241.

Suppe, F. (Ed.). The structure of scientific theories. 2. ed. Urbana/Illinois: University of Illinois Press, 1977 .

Тамвоцо, L. Metametodologia e fini della scienza a partire da Laudan. Trieste, 2008. Tese (Doutorado em Filosofia). Università degli Studi di Trieste.

ZaLta, E. N. (Ed.). Stanford encyclopedia of philosophy - Winter 2011 Edition. Stanford, CA: Metaphysics Research Lab, 2011. Disponível em: <http://plato.stanford.edu/archives/win2011/entries/thomas$\mathrm{kuhn} />$. 